\title{
CD109 expression is upregulated in penile squamous cell carcinoma
}

\author{
FENGYUN DONG ${ }^{1 *}$, JIN WANG $^{2,3^{*}}$, YINGHUA XU ${ }^{4}$, ZUOWANG CHENG $^{4}$, \\ XIAOCUI CHEN ${ }^{1}$, YIFAN WANG ${ }^{5}$ and JU LIU ${ }^{1}$
}

\begin{abstract}
${ }^{1}$ Medical Research Center, Shandong Provincial Qianfoshan Hospital, Shandong University, Jinan, Shandong 250014;
${ }^{2}$ School of Basic Medical Sciences, Shandong University, Jinan, Shandong 250012; ${ }^{3}$ Department of Urology, Shandong Provincial Qianfoshan Hospital, Shandong University, Jinan, Shandong 250014; ${ }^{4}$ Taishan Medical College, Tai'an, Shandong 271021; ${ }^{5}$ Weifang Medical College, Weifang, Shandong 261053, P.R. China
\end{abstract}

Received May 12, 2016; Accepted July 28, 2017

DOI: $10.3892 / 01.2017 .6975$

\begin{abstract}
Cluster of differentiation (CD) 109 is a glycosylphosphatidylinositol-anchored cell surface glycoprotein and a co-receptor for transforming growth factor $\beta$. The expression of CD109 has been detected in squamous cell carcinoma of the lung, esophagus, skin and gallbladder. The aim of the present study was to evaluate CD109 expression in penile squamous cell carcinoma (PSCC). CD109 expression in PSCC tumor and adjacent tissues from 45 specimens in tissue microarrays was examined by immunohistochemical analyses. In addition, 3 fresh surgical samples of PSCC were collected and examined for their CD109 mRNA and protein levels by reverse transcription-quantitative polymerase chain reaction, western blotting and immunofluorescence staining. CD109 transcription and expression were significantly higher in the PSCC tissues compared with adjacent normal penile tissues, and its expression was restricted to squamous cells. However, CD109 expression level was not associated with the PSCC differentiation grade. These results suggest that $\mathrm{CD} 109$ may be associated with the pathogenesis of PSCC, and may therefore be a potential therapeutic target.
\end{abstract}

\section{Introduction}

Penile cancer (PC) significantly affects male physical, mental and sexual health. In Western Europe and the United States, PC accounts for $0.4-0.6 \%$ of all cases of malignancy,

Correspondence to: Professor Ju Liu, Medical Research Center, Shandong Provincial Qianfoshan Hospital, Shandong University, 16766 Jingshi Road, Jinan, Shandong 250014, P.R. China

E-mail: ju.liu@sdu.edu.cn

${ }^{*}$ Contributed equally

Key words: penile squamous cell carcinoma, CD109, tissue microarray, biomarker whereas its incidence is higher in the developing nations of Asia, Africa and South America (1,2). Penile squamous cell carcinoma (PSCC), which comprises the majority of cases of PC, arises from the squamous epithelium of the glans, coronal sulcus or inner preputial surface (3). It is most common in 40-60 year-old patients with a redundant prepuce or phimosis (4), and is classically graded using the Broders classification system as low-(I-II) or high-grade (III-IV) lesions (5). PSCC causes significant morbidity and mortality in patients throughout the world. Despite advances in treatment, the prognosis of PSCC remains poor; a large-scale population-based investigation indicated that the survival of the patients with PSCC has not improved during the previous 20 years (6). When identified, PSCC-specific biomarkers may serve as chemotherapeutic targets. In addition, combinations of the biomarkers may provide diagnostic and prognostic value for clinical treatment. At present, relatively few efficient biomarkers for PSCC have been identified (7).

Cluster of differentiation (CD) 109, a glycosylphosphatidylinositol-anchored glycoprotein, is one of the members of the $\alpha 2$ macroglobulin/C3, C4, C5 family (8). Its physiological functions are largely unknown (9). CD109 binds to transforming growth factor- $\beta 1$ (TGF- $\beta 1$ ) and promotes the internalization of TGF- $\beta$ receptors (10-12). Analyses of CD109 gene expression pattern in human tissues indicated that its transcript is primarily expressed in the testis (13). Elevated expression of the CD109 gene and/or protein has been detected in lung, esophageal, skin, gallbladder and cervical squamous cell carcinomas (SCCs) (14-18). However, CD109 expression in PSCC has yet to be studied.

The aim of the present study was to investigate the expression of CD109 and its association with tumor grade in tumor tissue from patients with PSCC. The expression of CD109 in PSCC was examined by immunohistochemistry, immunofluorescence, western blotting and reverse transcription-quantitative polymerase chain reaction (RT-qPCR) in tissue samples and tissue microarrays (TMAs). The results suggested that CD109 expression was significantly increased in PSCC. Therefore, CD109 may be suitable as a novel biomarker or therapeutic target for PSCC. 


\section{Materials and methods}

Tissue samples. TMAs were obtained from US Biomax, Inc. (cat nos. PE601 and T223; Rockville, MD, USA), which included 38 human PSCC and 7 adjacent normal tissues (age range, 20-84 years; mean age, 54.56 \pm 13.83 ). Data regarding the specimens was provided by the manufacturer. A total of 3 fresh PSCC samples (age range, 56-79 years; mean age, $64.67 \pm 10.21)$ were collected between July 2015 and March 2016 at the Department of Urology at Shandong Provincial Qianfoshan Hospital, Shandong University (Jinan, China), in accordance with the code established by the Ethical Committee of Shandong University. Written, informed consent was obtained for the use of all patient samples. Samples were snap-frozen in liquid nitrogen and stored at $-80^{\circ} \mathrm{C}$ prior to use.

Immunohistochemistry. Immunohistochemistry on TMAs were performed as previously described (19). Briefly, the TMAs were dewaxed in xylene, rehydrated with graded alcohols and subjected to heat-induced epitope retrieval. Subsequent to washing, the TMAs were incubated overnight at $4^{\circ} \mathrm{C}$ with a rabbit polyclonal anti-CD109 antibody (dilution, 1:50; cat. no., HPA009292; Sigma-Aldrich; Merck KGaA, Darmstadt, Germany), and then incubated with a horseradish peroxidase-conjugated goat anti-rabbit secondary antibody (dilution, 1:100; cat. no., SA00001-2; ProteinTech Group, Inc.; Wuhan Sanying Biotechnology, Wuhan, China) for $90 \mathrm{~min}$ at room temperature. Antibody binding was visualized by incubation for $1 \mathrm{~min}$ with a solution of 1 drop of 3,3'-diaminobenzidine (20x DAB) per $1.0 \mathrm{ml}$ of DAB substrate buffer (cat. no., ZLI-9017; Origene Technologies, Inc., Beijing, China). The TMAs were then counterstained with EnVision FLEX hematoxylin (Dako; Agilent Technologies, Inc., Santa Clara, CA, USA) for $1 \mathrm{~min}$, and dehydrated through five grades of alcohol (50, 75, 80, 96 and 99\%) and xylene.

Evaluation of immunohistochemical staining. Subsequent to staining, images of the TMAs were captured with an Olympus FSX100 imaging system (Olympus Corporation, Tokyo, Japan) and analyzed by ImagePro Plus 6.0 software (Media Cybernetics, Inc., Rockville, MD, USA). Integral optical density (IOD) and percentage of expression (PE) were calculated and analyzed.

$R T$ - $q P C R$. Total RNA from the fresh PSCC samples and paired adjacent tissues was extracted with the E.Z.N.A. ${ }^{\circledR}$ Total RNA kit II (cat. no., R6934-02; Omega Bio-Tek, Inc., Norcross, GA, USA) according to the manufacturer's protocol. RT was performed using the RevertAid First Strand cDNA synthesis kit (cat. no., K1622; Thermo Fisher Scientific, Inc.; Waltham, MA, USA). qPCR was performed using SuperRealPreMix Plus with SYBR Green (cat. no., FP205-02; Tiangen Biotech Co., Ltd., Beijing, China) on the ViiA7 DX Real-Time PCR system (Thermo Fisher Scientific, Inc.) as follows: $95^{\circ} \mathrm{C}$ for $15 \mathrm{~min}$ followed by 40 cycles of $95^{\circ} \mathrm{C}$ for $10 \mathrm{sec}, 60^{\circ} \mathrm{C}$ for $20 \mathrm{sec}$ and $72^{\circ} \mathrm{C}$ for $32 \mathrm{sec}$. The sequences of primers for CD109 and GAPDH are included in Table I. All PCR reactions were repeated in triplicate. CD109 gene expression was assessed by comparing the relative expression level of CD109 with the internal reference GAPDH by the $2^{-\Delta \Delta \mathrm{Cq}}$ method (20).
Western blot analysis. Patient tissues were homogenized in radioimmunoprecipitation assay buffer (20 mM Tris $\mathrm{pH} 7.5$, $150 \mathrm{mM} \mathrm{NaCl}, 50 \mathrm{mM} \mathrm{NaF}, 1 \%$ NP40, 0.1\% DOC, 0.1\% SDS, $1 \mathrm{mM}$ EDTA, $1 \mathrm{mM}$ PMSF, $1 \mu \mathrm{g} / \mathrm{ml}$ leupeptin) and proteins were collected in the supernatant following centrifugation at $10,000 \mathrm{x} \mathrm{g}$ at $4^{\circ} \mathrm{C}$ for $15 \mathrm{~min}$. Protein concentrations were determined using a bicinchoninic acid assay (Bio Rad Laboratories, Inc., Hercules, CA, USA). An equal amount of protein per lane $(30 \mu \mathrm{g})$ from each sample was electrophoresed on a $10 \%$ SDS-PAGE gel, then transferred to a polyvinylidene fluoride membrane. The membrane was blocked with $2.5 \%$ non-fat milk in Tris-buffered saline with Tween-20 (TBST) at $37^{\circ} \mathrm{C}$ for $90 \mathrm{~min}$ prior to being incubated with the primary antibody overnight at $4^{\circ} \mathrm{C}$. Subsequent to washing with TBST 3 times, the membrane was incubated with the secondary antibody at $37^{\circ} \mathrm{C}$ for $1 \mathrm{~h}$. The primary antibodies used were rabbit polyclonal anti-CD109 antibody (dilution, 1:500; cat. no., 18715-1-AP; ProteinTech Group Inc.) and rabbit polyclonal anti-GAPDH (dilution, 1:3,000; cat. no., 10494-1-AP; ProteinTech Group, Inc.; Wuhan Sanying Biotechnology). The secondary antibody was horseradish peroxidase-conjugated anti-rabbit IgG (dilution, 1:6,000; cat. no., SA00001-2; ProteinTech Group, Inc.; Wuhan Sanying Biotechnology). The membranes were visualized with an enhanced chemiluminescence reagent (cat. no., WBKLS0500; Merck KGaA).

Immunofluorescence. The fresh PSCC samples and matching adjust tissues were frozen in optimal cutting temperature compound and cut into $6 \mu \mathrm{M}$ sections. The sections were fixed with pre-cooled 95\% methyl alcohol at room temperature for $5 \mathrm{~min}$, washed 3 times with PBS and stained with a polyclonal rabbit anti-human CD109 antibody (dilution, 1:50; cat. no., HPA009292; Sigma-Aldrich; Merck KGaA) overnight at $4^{\circ} \mathrm{C}$. Subsequent to washing, the sections were incubated with an Alexa546-labeled anti-rabbit secondary antibody (1:200; cat. no., A10040; Thermo Fisher Scientific, Inc.) at room temperature for $1 \mathrm{~h}$. Nuclear staining was performed with DAPI (cat. no., 10236276001; Roche Diagnostics GmbH, Mannheim, Germany) and samples were imaged with a fluorescence microscope at x100 magnification (Olympus Corporation).

Statistical analysis. The student's t-test was used for comparison of two groups. Analysis of variance with post-hoc Tukey's honest significant difference test was used for multiple comparisons. $\mathrm{P}<0.05$ was considered to indicate a statistically significant difference. All statistical analyses were performed using SPSS 19.0 statistical software (IBM Corp., Armonk, NY, USA).

\section{Results}

CD109 is overexpressed in PSCC tissues from TMAs. CD109 expression in human PSCC tissues was analyzed by immunohistochemical staining using TMAs with the anti-CD109 antibody, as previously described (17). In the normal penile tissues, CD109 expression was relatively low and confined primarily to the basal cells of the epidermis (Fig. 1A). In the well, moderately and poorly differentiated PSCC samples, the sheets or strands of malignant squamous cells exhibited 
Table I. Primer sequences.

\begin{tabular}{llrr}
\hline Gene & \multicolumn{1}{c}{ Sequence $\left(5^{\prime}-3^{\prime}\right)$} & Size $(\mathrm{bp})$ & $T_{\mathrm{m}}\left({ }^{\circ} \mathrm{C}\right)$ \\
\hline Cluster of differentiation 109 & & & 58.33 \\
Forward & GAAGCCATCTCTCAACTTCACA & 146 & 59.92 \\
Reverse & TTCCACTGTTAGATCCGCTCC & & 61.03 \\
GAPDH & & 240 & 68.32 \\
Sense & TGATGACATCAAGAAGGTGGTGAAG \\
Anti-sense & TCCTTGGAGGCCATGTGGGCCAT & & \\
\hline
\end{tabular}

$T_{\mathrm{m}}$, melting temperature; $\mathrm{CD}$, cluster of differentiation.

A

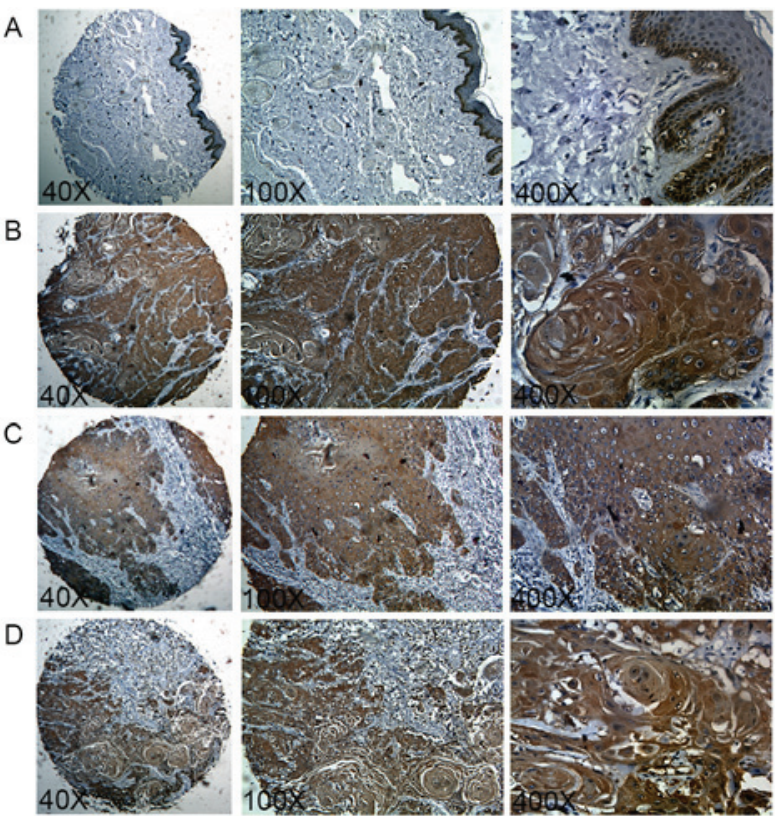

Figure 1. CD109 expression in PSCC tissue microarrays. Representative images of CD109 immunostaining in (A) normal penile tissue, (B) well-differentiated PSCC, (C) moderately-differentiated PSCC and (D) poorly-differentiated PSCC at magnification, x40, x100 and x400. CD, cluster of differentiation; PSCC, penile squamous cell carcinoma.

evident brownish CD109 staining in the membrane and cytosol (Fig. 1B-D). No positive staining was observed in other cell types, including vascular endothelial cells, pericytes, fibroblasts and gland cells. The IOD and PE were significantly higher in PSCC compared with the normal penile tissue (IOD, 17.32 vs. 5.36, $\mathrm{P}<0.05$; $\mathrm{PE}, 19.48 \%$ vs. $7.37 \%$, $\mathrm{P}<0.05$; Fig. $2 \mathrm{~A}$ and $\mathrm{B})$. It was previously identified that CD109 expression was inversely correlated with tumor grade in cutaneous and esophageal SCCs $(16,17)$. However, no statistically significant association of tumor grade with IOD $(\mathrm{P}=0.27)$ or $\mathrm{PE}(\mathrm{P}=0.12)$ was identified between well, moderately and poorly differentiated PSCCs (Table II).

mRNA and protein levels of CD109 are elevated in fresh surgical samples of PSCC. A total of 3 fresh surgical samples of PSCC were collected, and CD109 expression was examined with RT-qPCR, western blotting and immunofluorescence. As indicated in Fig. 3A, the mRNA level of CD109 was significantly upregulated in PSCC tumors compared with normal adjacent tissues in all 3 patients $(\mathrm{P}<0.01, \mathrm{P}<0.01$ and $\mathrm{P}<0.05$, respectively). Western blotting demonstrated a markedly higher protein level of CD109 in PSCC tissues compared with the CD109 expression in normal adjacent tissues, which was absent or low (Fig. 3B). The immunofluorescence staining of the fresh tissue sections demonstrated a similar expression pattern as the TMAs; CD109 was highly expressed in the malignant squamous cells of PSCC tissue, whereas there was low CD109 expression in the basal cells of the normal epidermis (Fig. 3C). Therefore, it was demonstrated that CD109 expression is upregulated in the malignant squamous cells of PSCC tissue.

\section{Discussion}

Approximately $95 \%$ of cases of PC are of squamous epithelial origin, including in situ and invasive PSCCs (4). Previous studies have identified a number of biomarkers for PSCC, including p53, cyclin D1 and Ki-67 (7). However, none of them are associated with lymph node metastases of PSCC or exhibit prognostic value (7). It is important to identify an appropriate biomarker for the early diagnosis or prognosis of PSCC. CD109 was previously detected in human tumor cell lines, including glioblastoma, squamous cell carcinoma, osteosarcoma and melanoma (13). In the present study, it was demonstrated that the CD109 protein was highly expressed in the malignant squamous cells of PSCC TMAs. The expression pattern was validated in fresh surgical samples by immunofluorescence, RT-qPCR and western blotting. These results suggest that CD109 may be associated with the pathogenesis of PSCC.

CD109 expression has been identified in normal squamous cells of the skin at a low level (17). In addition, CD109 is highly expressed in SCCs of various origins. For example, high-level expression of CD109 is frequently detected in lung and oral cavity SCC $(15,21)$; Zhang et al (14) identified that CD109 expression was significantly higher in cervical SCC tissue compared with endometrial adenocarcinoma tissue. In our previous studies, we evaluated CD109 expression in a variety of tumor tissues with immunohistochemical methods, and observed a significantly higher expression of CD109 in SCCs of the skin, esophagus and gallbladder, relative to non-cancer tissue (16-18). In the present study, it was observed that CD109 is located on the membrane and in the cytosol of the squamous cells of PSCC tumor tissue, which is consistent with the 
Table II. Association of cluster of differentiation 109 expression with the tumor differentiation grade in penile squamous cell carcinoma.

\begin{tabular}{lcccr}
\hline & \multicolumn{3}{c}{ Tumor differentiation } & \\
\cline { 2 - 4 } Immunohistochemical characteristics & Well $(\mathrm{n}=22)$ & Moderately $(\mathrm{n}=9)$ & Poorly $(\mathrm{n}=4)$ & P-value \\
\hline Integral optical density & $19.53 \pm 2.46$ & $14.00 \pm 2.54$ & $12.60 \pm 4.31$ & 0.27 \\
Percentage of expression & $22.25 \pm 2.40$ & $13.90 \pm 2.24$ & $16.81 \pm 5.72$ & 0.12 \\
\hline
\end{tabular}

Data are expressed as the mean \pm the standard error of the mean.

A

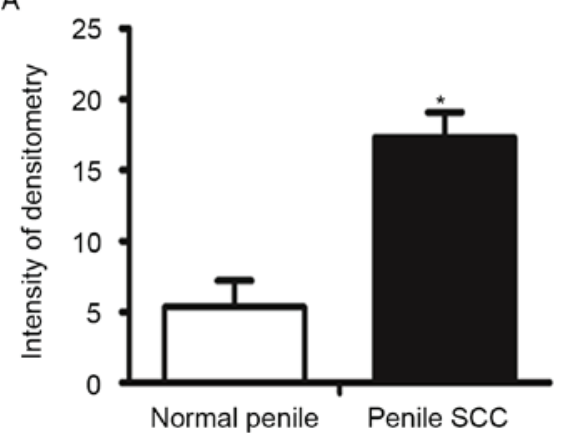

B

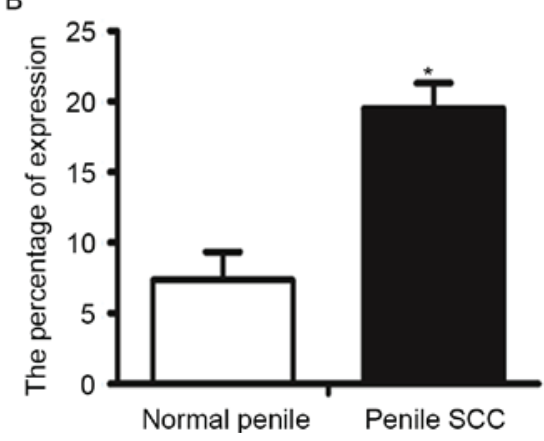

Figure 2. Analysis of CD109 expression in PSCC tissue microarrays. (A) Integral optical density of CD109 expression in normal penile and PSCC tissues. (B) Percentage of CD109 expression in normal penile and PSCC tissues. "P<0.05 compared with normal penile tissue. Data are presented as the mean \pm standard error of the mean. $\mathrm{CD}$, cluster of differentiation; PSCC, penile squamous cell carcinoma.
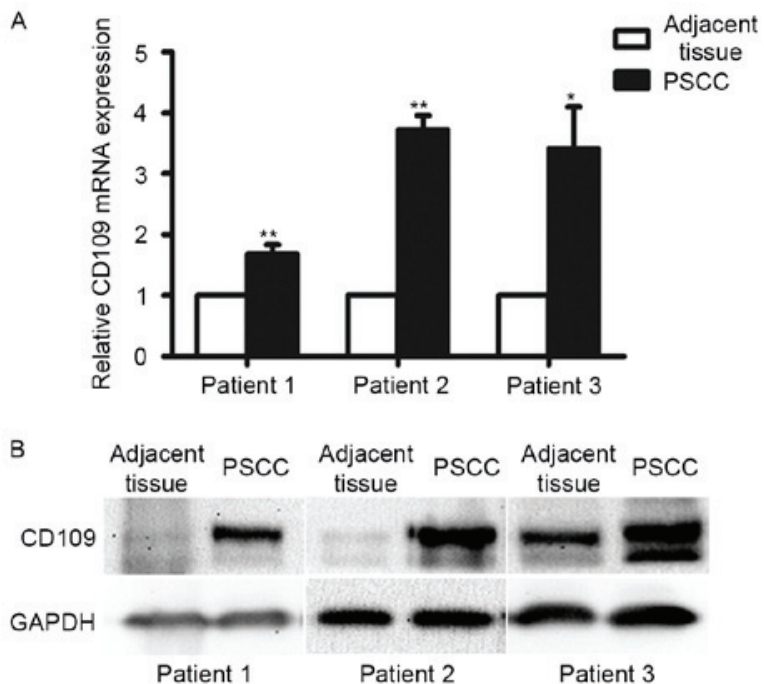

C

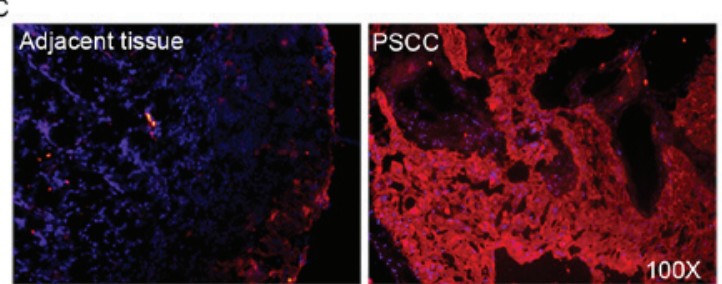

Figure 3. CD109 expression in fresh surgical samples of PSCC. (A) Reverse transcription-quantitative polymerase chain reaction analyses of CD109 mRNA expression in normal penile and PSCC tissue $(n=3) .{ }^{*} \mathrm{P}<0.05$, ${ }^{* * *} \mathrm{P}<0.01$. (B) Representative western blotting images of CD109 and GAPDH in normal penile and PSCC tissues. (C) Representative images of CD109 immunofluorescence staining in normal penile and PSCC tissue. CD, cluster of differentiation; PSCC, penile squamous cell carcinoma. previous data concerning SCCs in other organs. Therefore, CD109 expression may be upregulated in SCCs, irrespective of tissue origin.

CD109 expression has been detected in the endothelial cells of tumor-associated vessels $(22,23)$. CD109 is expressed in angiogenic vessels of hepatocellular carcinoma, and is associated with the regulation of tumor progression (22). In addition, CD109 expression was observed in the circulating endothelial cells of patients with blood cancer and glioblastomas $(24,25)$. In the present study, CD109 was not detected in the blood vessels of normal penile or PSCC tissue. CD109 expression is also absent in blood vessels of skin, esophagus, lung and gallbladder SCCs at all stages, and their adjacent normal tissues $(16-18,21)$. These data suggest that CD109 is not expressed in the vascular beds of squamous cells, and is not involved in SCC-associated angiogenesis.

The molecular mechanisms underlying the malignant transformation of a premalignant lesion in the penile remain largely unidentified. CD109 is a co-receptor for TGF- $\beta 1$. In human keratinocytes, CD109 binds to TGF- $\beta 1$ and forms a heteromeric complex with TGF- $\beta 1$ signaling receptors in the presence of TGF- $\beta 1$, resulting in the negative modulation of TGF- $\beta 1$ signaling (10-12). CD109 promotes TGF- $\beta$ receptor internalization and degradation by the regulation of Mothers against decapentaplegic homolog 7 (SMAD7) and SMAD-specific E3 ubiquitin protein ligase 2 activity in ubiquitin-mediated proteolysis $(8,26)$. In addition, CD109 overexpression inhibited TGF- $\beta 1$-induced transcriptional activation, antiproliferative effects and wound closure $(27,28)$. CD109 has also been demonstrated to regulate tumor growth and cell proliferation in oral cavity SCC and breast cancer 
cells $(21,29)$. TGF- $\beta$ signaling may cause tumor suppressive or tumor promoting effects. The tumor suppressing function is mediated by the SMAD signaling pathway, and the tumor promoting function is mediated by the phosphoinositide 3-kinase/Akt pathway (30-32). CD109 may regulate the development of PSCC by the inhibition of TGF- $\beta$ signaling.

In summary, the present study demonstrated that CD109 is highly expressed in PSCC tissues and may be suitable for use as a PSCC biomarker. As a surface protein, it may exhibit potential as a molecular target for PSCC therapy. Additional investigation into the role of CD109 in PSSC may facilitate the early diagnosis and treatment of the disease.

\section{Acknowledgements}

The present study was supported by a grant from the National Natural Science Foundation of China (grant no., 81570255). The authors are also grateful for the support from the Shandong Taishan Scholarship (Professor Ju Liu, Shandong University, Jinan, China).

\section{References}

1. Rubin MA, Kleter B, Zhou M, Ayala G, Cubilla AL, Quint WG, and Pirog EC: Detection and typing of human papillomavirus DNA in penile carcinoma: evidence for multiple independent pathways of penile carcinogenesis. Am J Pathol 159: 1211-1218, 2001.

2. Wabinga HR, Parkin DM, Wabwire-Mangen F and Nambooze S: Trends in cancer incidence in Kyadondo County, Uganda, 1960-1997. Br J Cancer 82: 1585-1592, 2000.

3. Greenberg RE: Surgical management of carcinoma of the penis. Urol Clin North Am 37: 369-378, 2010.

4. Bleeker MC, Heideman DA, Snijders PJ, Horenblas S, Dillner J and Meijer CJ: Penile cancer: Epidemiology, pathogenesis and prevention. World J Urol 27: 141-150, 2009.

5. Broders AC: Squamous-cell epithelioma of the skin: A study of 256 cases. Ann Surg 73: 141-160, 1921.

6. Verhoeven RH, Janssen-Heijnen ML, Saum KU, Zanetti R, Caldarella A, Holleczek B, Brewster DH, Hakulinen T, Horenblas S, Brenner H, et al: Population-based survival of penile cancer patients in Europe and the United States of America: No improvement since 1990. Eur J Cancer 49: 1414-1421, 2013.

7. Rodney S, Feber A, Arya M and Muneer A: Molecular markers in penile cancer. Curr Probl Cancer 39: 137-145, 2015.

8. Bizet AA, Tran-Khanh N, Saksena A, Liu K, Buschmann MD and Philip A: CD109-mediated degradation of TGF-beta receptors and inhibition of TGF- $\beta$ responses involve regulation of SMAD7 and Smurf2 localization and function. J Cell Biochem 113 238-246, 2012

9. Lin M, Sutherland DR, Horsfall W, Totty N, Yeo E, Nayar R, Wu XF and Schuh AC: Cell surface antigen CD109 is a novel member of the alpha(2) macroglobulin/C3, C4, C5 family of thioester-containing proteins. Blood 99: 1683-1691, 2002

10. Tam BY, Finnson KW and Philip A: Glycosylphosphatidylinosi tol-anchored proteins regulate transforming growth factor-beta signaling in human keratinocytes. J Biol Chem 278: 49610-49617, 2003.

11. Hagiwara S, Murakumo Y, Mii S, Shigetomi T, Yamamoto N, Furue H, Ueda M and Takahashi M: Processing of CD109 by furin and its role in the regulation of TGF-beta signaling. Oncogene 29: 2181-2191, 2010.

12. Litvinov IV, Bizet AA, Binamer Y, Jones DA, Sasseville D and Philip A: CD109 release from the cell surface in human keratinocytes regulates TGF- $\beta$ receptor expression, TGF- $\beta$ signalling and STAT3 activation: Relevance to psoriasis. Exp Dermatol 20: 627-632, 2011.
13. Hashimoto M, Ichihara M, Watanabe T, Kawai K, Koshikawa K, Yuasa N, Takahashi T, Yatabe Y, Murakumo Y, Zhang JM, et al: Expression of CD109 in human cancer. Oncogene 23: 3716-3720, 2004.

14. Zhang JM, Hashimoto M, Kawai K, Murakumo Y, Sato T, Ichihara M, Nakamura S and Takahashi M: CD109 expression in squamous cell carcinoma of the uterine cervix. Pathol Int 55: 165-169, 2005.

15. Sato T, Murakumo Y, Hagiwara S, Jijiwa M, Suzuki C, Yatabe Y and Takahashi M: High-level expression of CD109 is frequently detected in lung squamous cell carcinomas. Pathol Int 57: 719-724, 2007.

16. Dong F, Liu F, Yan S, Liu X, Jiang Z and Liu J: Elevated expression of CD109 in esophageal squamous cell carcinoma. Pathol Oncol Res 21: 1273-1275, 2015.

17. Dong F, Wang Y, Li L, Wang Y, Liu X and Liu J: CD109 expression is increased in cutaneous squamous cell carcinoma. J Dermatol 41: 947-949, 2014

18. Dong F, Lu C, Chen X, Guo Y and Liu J: CD109 is a novel marker for squamous cell/adenosquamous carcinomas of the gallbladder. Diagn Pathol 10: 137, 2015.

19. Dong F, Wang Y, Li L, Liu X, Yan S and Liu J: CD109 is expressed in epithelial cells of the juvenile thymus. Histopathology 66: 1041-1044, 2015

20. Livak KJ and Schmittgen TD: Analysis of relative gene expression data using real time quantitative PCR and the 2(-Delta Delta C(T)) method. Methods 25: 402-408, 2001

21. Hagiwara S, Murakumo Y, Sato T, Shigetomi T, Mitsudo K, Tohnai I, Ueda M and Takahashi M: Up-regulation of CD109 expression is associated with carcinogenesis of the squamous epithelium of the oral cavity. Cancer Sci 99: 1916-1923, 2008.

22. Ye BG, Sun HC, Zhu XD, Chai ZT, Zhang YY, Ao JY, Cai H, Ma DN, Wang CH, Qin CD, et al: Reduced expression of CD109 in tumor-associated endothelial cells promotes tumor progression by paracrine interleukin-8 in hepatocellular carcinoma. Oncotarget 7: 29333-29345, 2016.

23. Dong F, Cheng Y, Sun Q, Lu W, Zhang G, Li L, Allen TD and Liu J: CD109 is specifically expressed in endothelial cells of cutaneous cavernous haemangioma. Histopathology 67: 133-135, 2015.

24. Cuppini L, Calleri A, Bruzzone MG, Prodi E, Anghileri E, Pellegatta S, Mancuso P, Porrati P, Di Stefano AL, Ceroni M, et al: Prognostic value of CD109+ circulating endothelial cells in recurrent glioblastomas treated with bevacizumab and irinotecan. PLoS One 8: e74345, 2013.

25. Mancuso P, Calleri A, Gregato G, Labanca V, Quarna J, Antoniotti P, Cuppini L, Finocchiaro G, Eoli M, Rosti V and Bertolini F: A subpopulation of circulating endothelial cells express CD109 and is enriched in the blood of cancer patients. PLoS One 9: e114713, 2014

26. Bizet AA, Liu K, Tran-Khanh N, Saksena A, Vorstenbosch J, Finnson KW, Buschmann MD and Philip A: The TGF- $\beta$ co-receptor, CD109, promotes internalization and degradation of TGF- $\beta$ receptors. Biochim Biophys Acta 1813: 742-753, 2011.

27. Vorstenbosch J, Gallant-Behm C, Trzeciak A, Roy S, Mustoe T and Philip A: Transgenic mice overexpressing CD109 in the epidermis display decreased inflammation and granulation tissue and improved collagen architecture during wound healing. Wound Repair Regen 21: 235-246, 2013

28. Vorstenbosch J, Al-Ajmi H, Winocour S, Trzeciak A, Lessard L and Philip A: CD109 overexpression ameliorates skin fibrosis in a mouse model of bleomycin-induced scleroderma. Arthritis Rheum 65: 1378-1383, 2013.

29. Hockla A, Radisky DC and Radisky ES: Mesotrypsin promotes malignant growth of breast cancer cells through shedding of CD109. Breast Cancer Res Treat 124: 27-38, 2010.

30. Arteaga CL: Inhibition of TGFbeta signaling in cancer therapy. Curr Opin Genet Dev 16: 30-37, 2006.

31. Bierie B and Moses HL: Tumour microenvironment: TGFbeta: The molecular Jekyll and Hyde of cancer. Nat Rev Cancer 6: 506-520, 2006.

32. Matsuzaki K and Okazaki K: Transforming growth factor-beta during carcinogenesis: The shift from epithelial to mesenchymal signaling. J Gastroenterol 41: 295-303, 2006. 